\title{
RECENT ADVANCES IN ANTIMICROBIAL ACTIVITY OF PYRIMIDINES: A REVIEW
}

\author{
PRANALI A JADHAV*, ATUL BARAVKAR
}

Agriculture Development Trust's, Shardabai Pawar Institute of Pharmaceutical Sciences and Research, Shardanagar, Baramati, Maharashtra, India. Email: pranalijadhav024@gmail.com

Received: 25 November 2021, Revised and Accepted: 30 December 2021

ABSTRACT

Over the past era, development of small heterocycles as potential therapeutics has been a zone of major interest. A large number of pyrimidine derivatives are of considerable biological and chemical interest. Pyrimidine derivatives have shown numerous biological activities such as antimicrobial, antitubercular, anticancer, anticonvulsant, antidiabetic, antiviral, and anti-inflammatory. Being a heterocyclic compound, Pyrimidine finds its use for designing synthesis of newer biologically active structures, as its aromaticity makes it relatively stable, also reactive sites which allow for functionalization. Several amino derivatives of nitrogen-containing heterocycles such as pyrimidine, pyridine possess an antimicrobial activity. In this review, recent advancements in the antimicrobial activity of pyrimidine derivatives have been reported.

Keywords: Pyrimidine, Antimicrobial, Antibacterial, Antifungal.

(C) 2022 The Authors. Published by Innovare Academic Sciences Pvt Ltd. This is an open access article under the CC BY license (http://creativecommons.org/ licenses/by/4.0/) DOI: http://dx.doi.org/10.22159/ajpcr.2022v15i2.43686. Journal homepage: https://innovareacademics.in/journals/index.php/ajpcr

\section{INTRODUCTION}

Pyrimidine is the most important six-membered aromatic heterocyclic ring containing two nitrogen atoms. The replacement of $\mathrm{C}-\mathrm{H}$ units meta to each other in a benzene ring by two nitrogen atoms gives pyrimidine. The reactivities of 2,4,5 and 6 carbon atoms, as well as substituents attached to them, vary individually. Although the parent compound, pyrimidine is not widely used, many of its derivatives are found in commercial products or in nature [1-3] (Fig. 1).

In the past several decades there has been a significant increase in the preparation of pyrimidine derivatives and their biological activity. Many substituted pyrimidines have been reported to display a large panel of biochemical properties, including anticonvulsant, antibacterial, antitumor, antiviral, and antibiotic activities [4]. Variation of substituents on the pyrimidine nuclei could potentially affect the interaction of the molecules with biological targets. The wide range of biological activity and versatile synthetic applicability of these heterocyclic compounds will help the medicinal chemists to plan, organize and implement new approaches toward discovery of novel drugs. Thus, pyrimidine compounds received much attention from medicinal as well as synthetic organic chemists $[5,6]$.

\section{STRUCTURE ACTIVITY RELATIONSHIP OF PYRIMIDINES (FIG. 2)}

- As SAR studies give insights into the molecular properties causing receptor affinity and selectivity, The promising nature of compounds may be attributed to the substitutions at the hydrophobic domain.

- These compounds had electron-withdrawing and donating groups at the ortho, meta, and para position of the hydrophobic aryl ring. In overall, it was noticed that the substituted derivatives have more activity than the other derivatives.

- This may be because of the fact that substituted derivatives are better fitted into the receptor site.

\section{Position A}

Substitution at five-membered saturated heterocyclic ring leads to anticancer and antiviral activities.

\section{Position B}

i. Substitution at $2^{\text {nd }}$ position with five or six-membered saturated heterocyclic ring directs to anthelmintic, antiparkinsonian, expectorant activity, and treatment of GI disturbance. ii. $2^{\text {nd }}$ and $4^{\text {th }}$ position keto group substitution or amino substitution or mixed keto, amino groups substitution leads to anticancer, antiviral, antibacterial, antifungal, and treatment of respiratory tract infection and liver disorder.

\section{Position C}

Substitution at $5^{\text {th }}$ position with substituted amine or saturated distal heterocyclic ring or halogen leads to antibacterial and anticancer activities.

\section{Position D}

Fifth and $6^{\text {th }}$ position fused with other heterocyclic ring and $o, m$, $p$ substituted with aryl ring. This substitution leads to anticancer antiviral, antibacterial, vasodilation, and treatment of UTI [5,7-11].

\section{RECENT ADVANCES IN ANTIMICROBIAL ACTIVITY OF PYRIMIDINE DERIVATIVES}

Abd El-Aleam et al. synthesized a series of 1,2,4-triazolo[1,5-a] pyrimidine derivatives and screened for their antibacterial and antifungal activities as well as their safety profile. Synthesized compounds were evaluated for their antibacterial activity against five bacterial strains: E. coli, K. pneumoniae, A. baumannii, P. aeruginosa (Gram negative), and Methicillin-Resistant S. aureus (MRSA) (Grampositive) using ciprofloxacin as a positive control. The antifungal activity screening against two fungal species, C. albicans, and C. neoformans, was performed using fluconazole as a positive control. Furthermore, compounds displaying significant growth inhibition \% $(80-100 \%)$ at $32 \mu \mathrm{g} / \mathrm{mL}$ against any of the tested bacterial or fungal species were screened for their minimum inhibitory concentrations (MIC). Among the synthesized compounds both benzohydrazide derivatives 1 (Fig. 3) exerted high activity against the tested bacterial strains with MIC values $0.25-1 \mu \mathrm{g} / \mathrm{mL}$ [12].Panneerselvam and J R Mandhadi synthesized new series of antimicrobial thiosemicarbazide substituted pyrimidine derivatives by using thiosemicarbazide and ethyl 2-((2-amino5-carbamoyl-6-[substituted benzyl] pyrimidin-4-yl)oxy)acetate derivatives and subsequent addition of acetaldehyde and acetone. The designed compounds were screened for antibacterial activity against Staphylococcus aureus, Staphylococcus epidermidis, Micrococcus luteus, Bacillus cereus, Escherichia coli, Pseudomonas aeruginosa, and Klebsiella pneumonia in comparison with the standard drugs Ciprofloxacin and antifungal effect against Aspergillus niger and Aspergillus fumigates in comparison with the standard drug Ketoconazole. In accordance 
with the data obtained from antimicrobial activity, all the synthesized derivatives have shown good activity against the tested microbes. Among them, compound bearing 2-hydroxy and 3-chloro derivatives of thiosemicarbazide substituted pyrimidine 2 (Fig. 4) has shown good activity against all the tested organisms [13]. AlNeyadi et al. designed and synthesized a series of pyrimidine derivatives and evaluated their antimicrobial activity. Among them, compound 3 exhibited the best activity with the MIC values of $1.0 \mu \mathrm{g} / \mathrm{ml}$ against $E$. coli and Pseudomonas aeruginosa. Then, the antimicrobial activity of compound

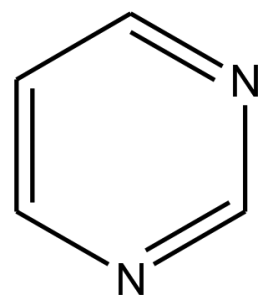

Fig. 1: Pyrimidine nucleus

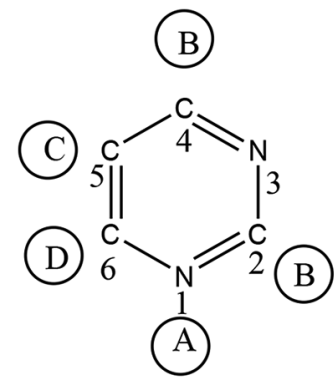

Fig 2: Positions for substitution on pyrimidine ring<smiles>[R][R]CNNC(=O)c1c[nH]c2nc([R])nn2c1=O</smiles>

Fig. 3: 1,2,4-triazolo[1,5-a] pyrimidine derivatives<smiles>[R]C/C=C\c1ccccc1/C(=C\C)c1nc(N)nc(OCC(=O)NNC(N)=S)c1C(N)=O</smiles>

$\mathrm{R}=2-\mathrm{OH}, 3-\mathrm{Cl}$ 2

Fig. 4: Thiosemicarbazide substituted pyrimidine derivatives
3 (Fig. 5) combined with amoxicillin was also been tested. Docking studies revealed that the formation of the covalent complex suggested that the enzyme would be permanently damaged, resulting in cell wall synthesis inhibition. Indeed, further work is required to confirm that the PBP enzyme is a target for our novel antibacterial agents [14].

Mantipally et al. designed and synthesized novel homopiperazine linked imidazo[1,2-a] pyrimidine derivatives. Synthesized compounds were also evaluated for their antimicrobial activity by cup plate diffusion method. Some of the synthesized compounds displayed remarkable antimicrobial activity relating to their standard drugs Gentamycin, Amphotericin B, and Ampicillin. Significantly, compound with the $-\mathrm{N}(\mathrm{Me})_{2}$ group was introduced on the homopiperazine 4 (Fig. 6) unit showed broad-spectrum activity against tested microbial strains [15].

The utility of the enaminonitriles for the synthesis of the pyrazole derivatives, diaminopyrimidine derivatives, pyrazolo[1,5-a] pyrimidines, triazolo[4,3-a] pyrimidines, and imidazo[1,2-a] pyrimidine derivatives was explored by A M farag and A M Fahim. The synthesized compounds were examined for antimicrobial strains. The most active compound was found to be $\mathbf{5}$ and compound $\mathbf{6}$ (Fig. 7) showed one of the highest observed activities against B. subtilis and Geotricum candidum. The increased antimicrobial activity might be due to the carboxyl group [16].

Shehab et al. synthesized series of pyrimidines and condensed pyrimidine derivatives. Antimicrobial activity of the prepared compounds was investigated against different bacterial and fungal species, such as E. Coli ATCC11229, listeria ATCC8729, S. aureus ATCC6538, Salmonella typhi ATCC14028, and Aspergillus niger OC10. The oxazolopyrimidine derivative 7 (Fig. 8) showed the highest antibacterial activity [17].

Al-Bogami et al. synthesized a series of novel fused pyrimidine derivatives possessing a trifluoromethyl moiety by the reaction of the enaminone named E-3-(dimethylamino)1-(4-(trifluoromethyl) phenyl) prop-2-en-1-one with a variety of heterocyclic amines under solvent-free mechanochemical condition utilizing nano-sized magnesium oxide catalyst. The newly

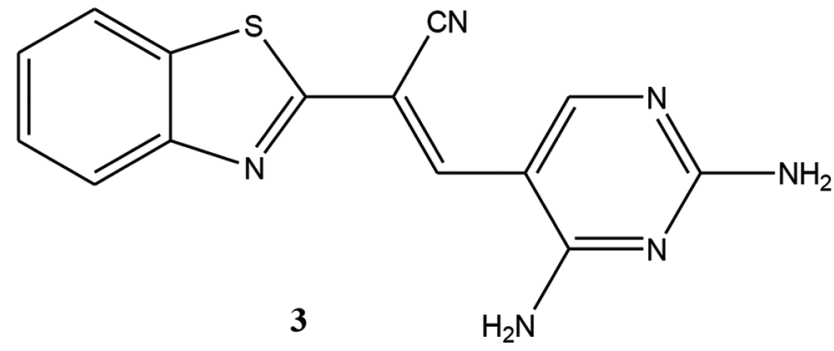

Fig. 5: Benzazole acrylonitrile-based pyrimidine derivatives

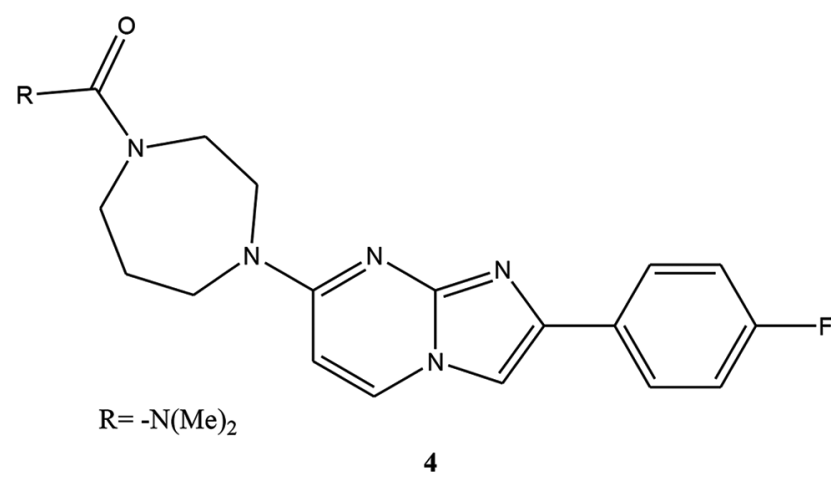

Fig. 6: Homopiperazine linked imidazo[1,2-a] pyrimidine derivatives 
synthesized compounds were evaluated for their in vitro antibacterial activity against Escherichia coli (ATCC25922) and Pseudomonas aeruginosa (ATCC27953) as examples of Gram-negative bacteria and Staphylococcus aureus (ATCC29213) and Bacillus subtilis (NRRL-B-4219) as examples of Gram-positive bacteria. They were also evaluated for their in vitro antifungal potential against a representative panel of fungal strains, i.e., Candida albicans (ATCC10231). Compound 8b exhibited broad spectrum and remarkable antimicrobial activity, Moreover, 8d and 8j (Fig. 9) showed good antimicrobial efficacy toward the tested organisms [18].

Dofe et al. developed convenient and facile methodology for the synthesis of new series of pyrazole and pyrimidine derivatives under ultrasound irradiation. The synthesized compounds were screened for their antimicrobial activity against four bacteria (Staphylococcus aureus, Bacillus subtilis, Escherichia coli, Pseudomonas aeruginosa) and two fungi (Candida albicans, Aspergillus niger). Among the synthesized compound, one without substituent, having dichloro substituent, and with chloro, methyl substituent (Fig. 10) exhibited potent activity, indicated that compounds with electron-donating groups are responsible for the enhanced activity of the compounds [19].

Veeraswamy et al. prepared a series of novel pyrido[2,3-d] pyrimidine derivatives starting from 2-amino-3-cyano-4-trifluoromethyl-6-phenyl<smiles>COC(=O)c1ccc(C(=O)c2cnc3nncn3c2N)cc1</smiles>

5<smiles>Nc1c(C(=O)c2ccc(C(=O)O)cc2)cnc2nc3ccccc3n12</smiles>

6

Fig. 7: Triazolo[4,3-a] pyrimidines and imidazo[1,2-a] pyrimidine derivatives

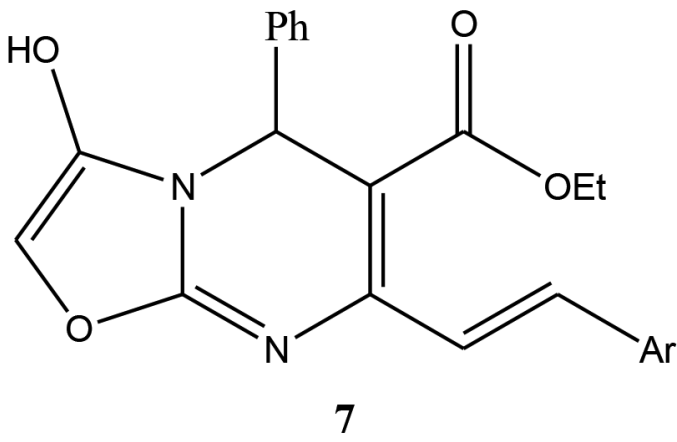

Fig. 8: Oxazole condensed pyrimidine derivatives pyridine via Grignard's reaction, cyclization followed by coupling with aliphatic and cyclic amines. All the compounds were screened for antibacterial, minimum bactericidal concentration (MBC), as well

\begin{tabular}{|c|c|c|}
\hline & $\mathrm{R}_{1}$ & $\mathrm{R}_{2}$ \\
\hline $\mathrm{b}$ & $4-\mathrm{ClPh}$ & $\mathrm{H}$ \\
\hline $\mathrm{d}$ & $\mathrm{CH}_{3}$ & $\mathrm{H}$ \\
\hline $\mathrm{j}$ & $\mathrm{NH}_{2}$ & $3-\mathrm{CF}_{3} \mathrm{PhN}=\mathrm{N}$ \\
\hline
\end{tabular}<smiles>[R]c1nn2c(-c3ccc(C(F)(F)F)cc3)c([2H])c([2H])nc2c1[R]</smiles>

Fig. 9: Fused pyrimidine derivatives possessing a trifluoromethyl moiety<smiles>[R][R][R]=[R][R]</smiles>

Fig. 10: Thiopyrimidine derivatives<smiles>[R12]NC(=O)c1nc([R])c2c(C(F)(F)F)cc(-c3ccccc3)nc2n1</smiles>

$\mathrm{R}=\mathrm{C}_{6} \mathrm{H}_{5}, 4-\mathrm{MeOC}_{6} \mathrm{H}_{5}$

$\mathrm{NR}^{1} \mathrm{R}^{2}=$<smiles>CN1CCNCC1</smiles><smiles>OCCN1CCNCC1</smiles>

Fig. 11: Pyrido[2,3-d] pyrimidine derivatives 
as antifungal and minimum fungicidal concentration (MFC) activities. Among the screened compounds, 10 (Fig. 11) exhibiting promising activity have been identified. The results reveal that the compound pyrido[2,3-d] pyrimidine derivative altered the sterol profile which may exert its antifungal activity through inhibition of ergosterol biosynthesis and could be an ideal candidate for antifungal therapy [20].

Mohamed et al. designed and synthesized new pyrimidine derivatives. Some of the newly synthesized compounds were assayed in vitro for their antimicrobial activity against two gram-negative bacteria: namely, Pseudomonas aeruginosa and Escherichia coli, and two gram-positive bacteria: Staphylococcus aureus and Bacillis subtilis and two fungal species, namely: Aspergillus flavus and Candida albicans. The fungicide Colitrimazole and the bactericides Ampicillin were used as references to evaluate the potency of the tested compounds under the same conditions. Hydrazino derivative (11) and acetohydrazide derivative 12 (Fig. 12) were found to have pronounced inhibition effect [21].

Andrews et al. synthesized and compared the antibacterial activities of pyrimidine derivatives. The newly synthesized pyrimidine derivatives<smiles>COc1ccc(-c2nc(NN)[nH]c(=O)c2C#N)cc1</smiles><smiles>COc1ccc(-c2nc(NNC(C)=O)[nH]c(=O)c2C#N)cc1</smiles>

Fig. 12: Hydrazino pyrimidine derivative<smiles>[R]c1ccc(C2NC([X])NC(C)=C2c2nnc(S)[nH]2)cc1[R]</smiles><smiles></smiles>

$\mathrm{R}=\mathrm{H}, \mathrm{Cl}, \mathrm{N}\left(\mathrm{CH}_{3}\right)_{2}, \mathrm{OH}$

$\mathrm{R}_{1}=\mathrm{H}, \mathrm{NO}_{3}$

13

Fig. 13: Triazole substituted pyrimidines were screened for their antibacterial activity in vitro against Pseudomonas aeruginosa, Staphylococcus aureus, and Escherichia coli, using agar well disk diffusion method. Among the synthesized derivatives, triazole substituted compounds 13 (Fig. 13) have shown higher antibacterial inhibition when compared to the thiadiazole derivatives [22].

Khalifa et al. synthesized a series of novel substituted thioxopyrimidine and thiazolo[3,2-a] pyrimidine compounds (Fig. 14) that combine various heteroaryl rings via Biginelli one-pot three-component reaction. Antibacterial activity was tested against several bacterial strains isolated from food of animal origin: one pathogenic Gram +ve bacteria stain, Staphylococcus aureus, and two pathogenic Gram -ve bacteria stains, Salmonella typhimurium, and Pseudomonas aeruginosa. For antifungal activity, Candida albicans and Aspergillus flavus were utilized [23].

Okasha et al. synthesized new series of chromeno pyrimidine derivatives. All the newly synthesized compounds were screened for their in vitro antimicrobial activity at $25 \mu \mathrm{g} / \mathrm{mL}$ to determine the zone of inhibition against four Gram-positive bacteria: Staphylococcus aureus (RCMB 000106), Staphylococcus epidermidis (RCMB 000107), Bacillus subtilis (RCMB 000108), Bacillus pumilus (RCMB 000109), and two Gram-negative pathogenic bacteria: Pseudomonas aeruginosa (RCMB 000102), Escherichia coli (RCMB 000103) using two standard antibiotics (ampicillin, streptomycin) as reference drugs, and three fungi: Aspergillus fumigatus (RCMB 002003), Candida albicans (RCMB 005002) and Saccharomyces cerevisiae (RCMB 006002) using two standard antibiotics (mycostatine, clotrimazole) as reference drugs. It was demonstrated that 7H-benzochromenopyrimidine (15) and

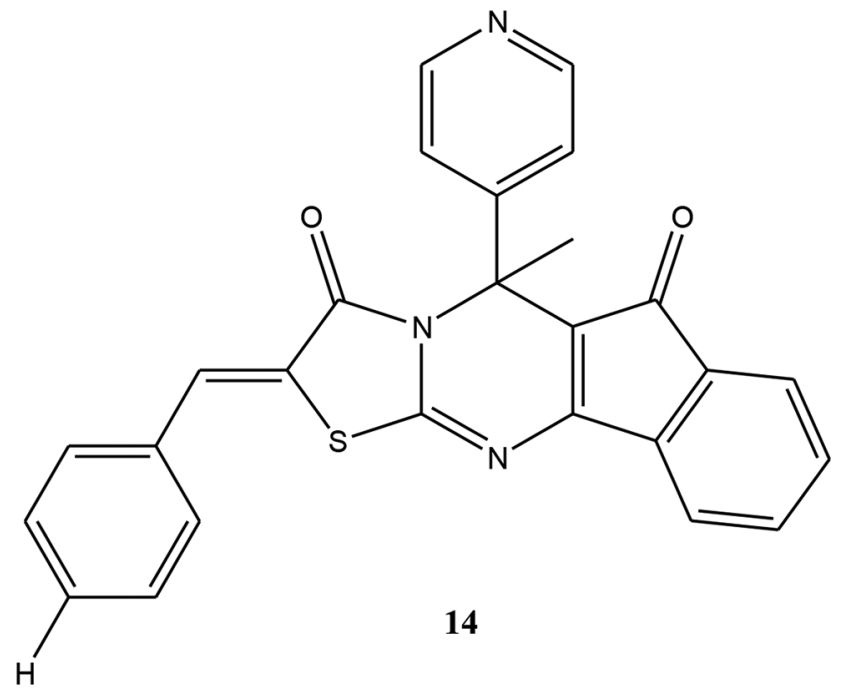

Fig. 14: Thiazolo[3,2-a] pyrimidine compounds

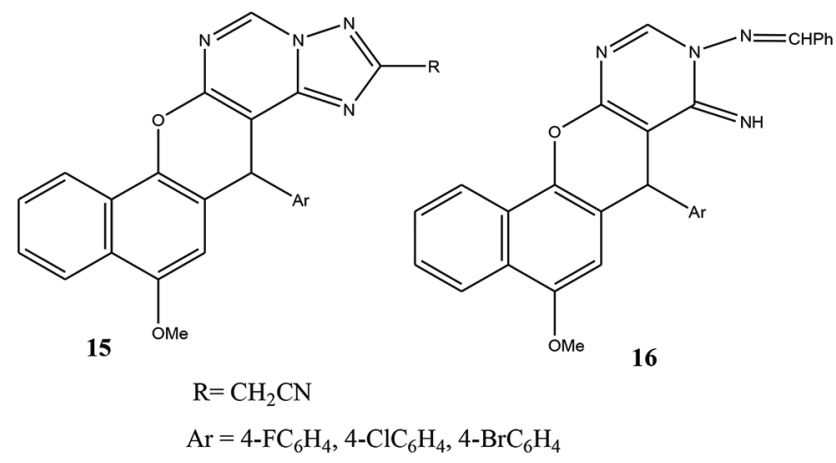

Fig. 15: Chromeno pyrimidine derivatives 
derivatives of $14 \mathrm{H}$-benzochromenotriazolopyrimidine 16 (Fig. 15) exhibited the most promising antibacterial activities compared to the reference antimicrobial agents [24].

Virupakshi et al. have reported the design, synthesis, characterization \& biological activity of novel thieno [2,3-d] pyrimidine derivatives. The final compounds were screened for their antibacterial activity against Staphylococcus aureus and Bacillus subtilis from the Grampositive group of bacteria. Pseudomonas aeruginosa and Escherichia coli from Gram-negative group of bacteria. Antifungal activity against Aspergillus niger and Candida albicans. The structure and biological activity relationship of title compounds indicate that the presence of electron-withdrawing groups such as $-\mathrm{CF}_{3}$ and $-\mathrm{OCF}_{3}$ attached to the phenyl ring and thiophene, Furan rings (Fig. 16) were responsible for good antimicrobial activity [25].

Al- Juboori and Mahmood have reported Synthesis, antimicrobial evaluation, density functional theory, and docking studies of some new 2-mercapto pyrimidine Schiff bases to display antimicrobial activity and antifungal activities. The synthesized derivatives were screened for their in vitro, antibacterial activity against two Grampositive bacteria: Bacillus subtilis and Staphylococcus aureus and Gram-negative bacteria: Klebsiella pneumoniae, Escherichia coli, and Salmonella typhi, and the results showed that most of them have good antibacterial activity. While their antifungal activity against four fungi species (Aspergillus fumigates, Aspergillus niger, Aspergillus terrus,

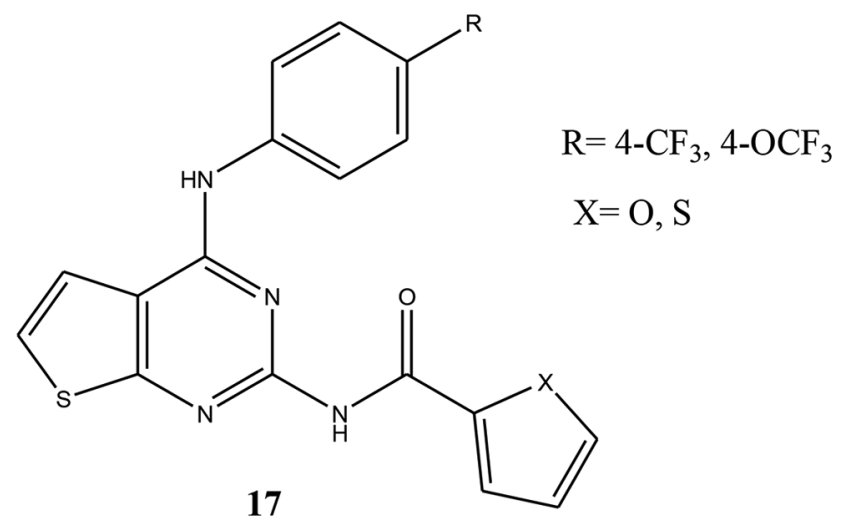

Fig. 16: Furan substituted thieno [2,3-d] pyrimidines<smiles>Oc1ccccc1/C=N\C(=S)Nc1ncccn1</smiles><smiles>S=C(/N=C\c1ccccc1)Nc1ncccn1</smiles>

19

Fig. 17: 2-mercapto pyrimidine Schiff bases and Rhizopus). Results obtained from molecular docking discovered that compounds with bulky phenyl groups (Fig. 17) are important for blocking the active centers of glucose -6-phosphate synthase in bacteria and fungi [26].

Khatri and Shah reported the effective microwave synthesis of bioactive Thieno $[2,3-d]$ pyrimidines. All of the synthesized compounds were tested for their antibacterial and antifungal activity (MIC) in vitro using two Gram-positive bacteria Staphylococcus aureus, Streptococcus pyogenes, two Gram-negative bacteria Escherichia coli, Pseudomonas aeruginosa, and three fungal strains Candida albicans, Aspergillus niger, Aspergillus clavatus. The compound (Fig. 18) was found to be exhibited significant antimicrobial activity [27].

Triloknadh et al. synthesized a series of thieno[2,3-d] pyrimidine alkyne Mannich base derivatives and thieno[2,3-d]pyrimidine 1,3,4-oxadiazole derivatives. All of the synthesized compounds were screened for their antibacterial activity against the four bacterial strains such as $S$. aureus, B. subtilis, E. coli, and P. aeruginosa on par with reference drug gentamicin. Structure activity relationship studies (SAR) revealed the change in the substitutions on the $\mathrm{C} 4$ position of thienopyridine ring and terminal phenyl ring (Fig. 19) leads to substantial changes in the biological activities [28].

Gupta et al. reported the synthesis of new pyrimidine-based derivatives and evaluated their antimicrobial activity against four different strains, viz two Gram-positive bacteria (Staphylococcus aureus and Streptococcus pyogenes) and two Gram-negative bacteria (Escherichia

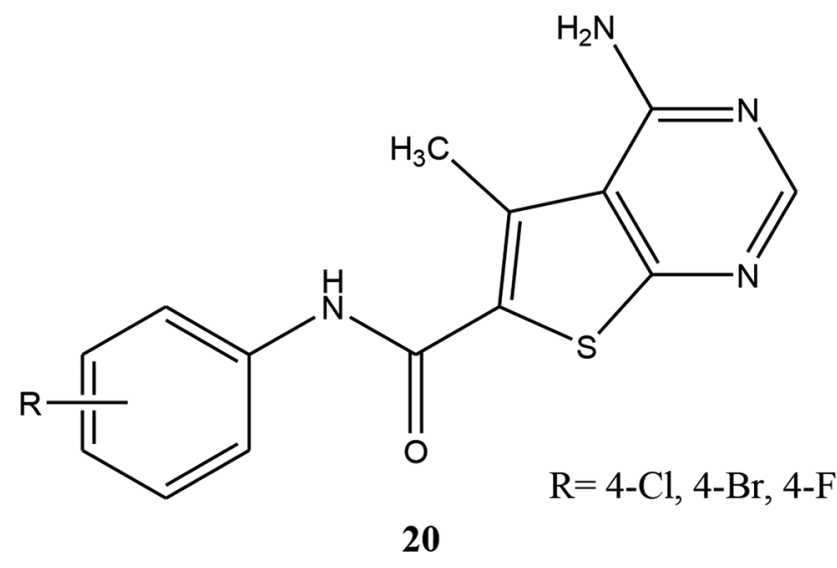

Fig. 18: Thieno $[2,3-d]$ pyrimidines<smiles></smiles>

Fig. 19: Thieno[2,3- d]pyrimidine 1,3,4-oxadiazole derivatives 


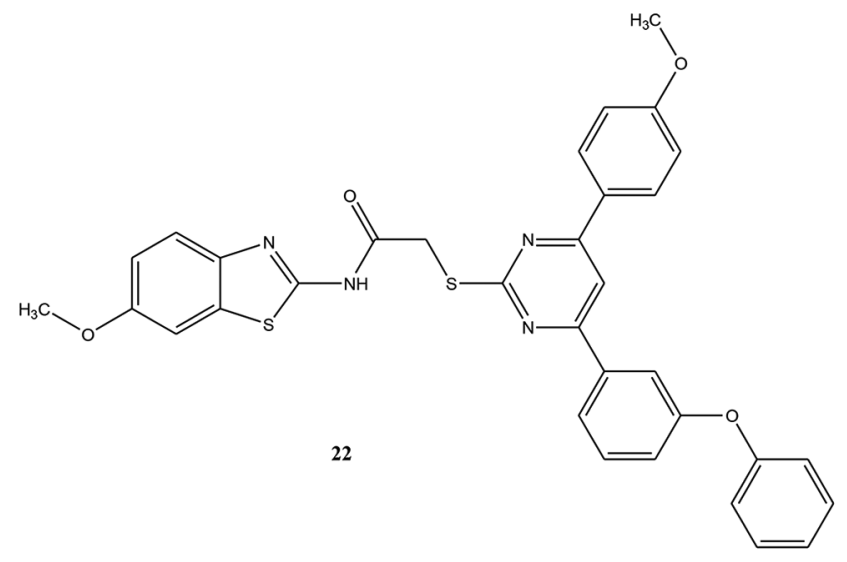

Fig. 20: Pyrimidine based derivatives

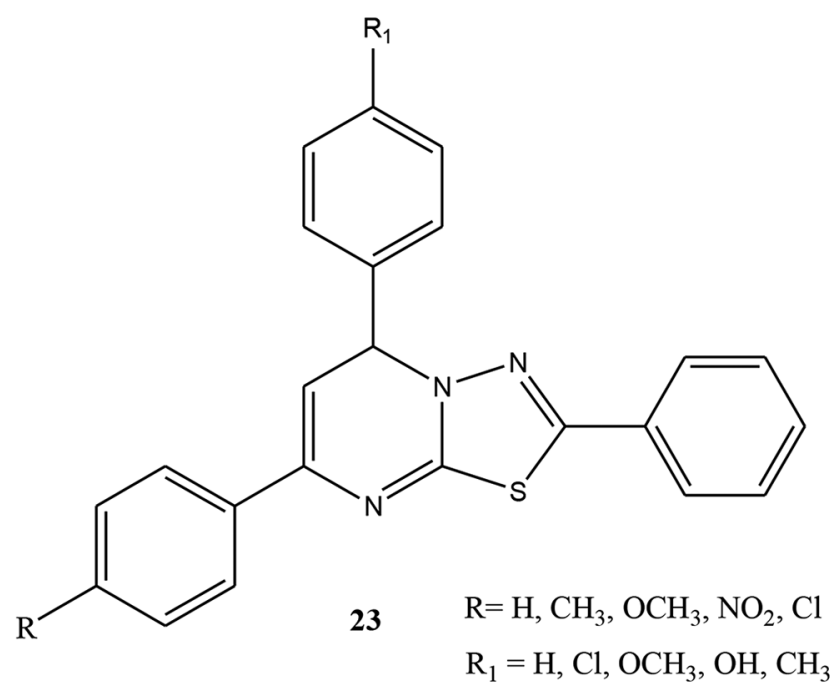

Fig. 21: 5,7-disubstituted-2-phenyl-5H-[1,3,4] thiadiazolo[3,2-a] pyrimidines

coli \& Pseudomonas aeruginosa), analyzed with standard drugs ampicillin, chloramphenicol, ciprofloxacin, \& norfloxacin. Antifungal activity was screened against Candida albicans, and Aspergillus niger organisms analyzed with standard drugs nystatin and griseofulvin. Some of the compounds $\mathbf{2 2}$ (Fig. 20) were effective as antimicrobial and antifungal agents [29].

Venkatesh et al. reported the synthesis of a series of 5,7-disubstituted2-phenyl-5H-[1,3,4] thiadiazolo[3,2-a]pyrimidine derivatives. The title compounds were synthesized by the reaction of substituted chalcones with 5-phenyl-1,3,4-thiadiazol-2-amine in n-butanol. Anti-microbial activity of the synthesized compounds was tested against seven microbial strains (Staphylococcus aureus, Bacillus subtilis, Escherichia coli, Shigella sp, Candida albicans, Aspergillus niger, Alternaria alternate) using the agar well diffusion method. The compounds (Fig. 21) displayed significant antimicrobial and antioxidant activities [30].

Madawali et al. synthesized a new series of pyrimidines of 6-chlorobenzimidazoles by the reaction of chalcone derivatives of 6-chlorobenzimidazole with guanidine nitrate in ethanol and aqueous solution of sodium hydroxide. The synthesized products have been tested for antibacterial activity against two Gram-positive bacteria viz., Bacillus subtilis, Staphylococcus aureus, and two Gram-negative bacteria viz., Proteus mirabilis and Escherichia coli. The antifungal activity of the products has been screened against two fungi viz., Aspergillus niger and Candida albicans by cup plate method. Many of these products (Fig. 22) showed significant activity [31].

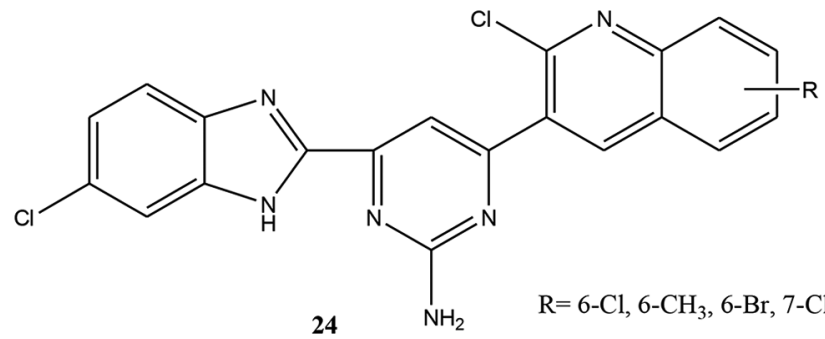

Fig. 22: Pyrimidines of 6-chlorobenzimidazoles

\section{CONCLUSION}

The literature reveals that compounds having pyrimidine nucleus possesses broad range of biological activities. Antimicrobial activity was significantly affected by slight change in substitution of pyrimidine rings. Substitutions at specific positions markedly enhance the activity. Hence, these findings will guide researchers to design and synthesize target compounds having pyrimidine nucleus with the hope that they may possess good antimicrobial activity.

\section{ACKNOWLEDGEMENT}

The authors acknowledge the support from Agriculture Development Trust's, Shardabai Pawar Institute of Pharmaceutical Sciences and Research, Shardanagar, Baramati, Maharashtra, India, 413115.

\section{AUTHORS' CONTRIBUTIONS}

Both authors contributed equally to writing the manuscript, analyzing the data, read and approved the manuscript.

\section{CONFLICT OF INTEREST}

None.

FUNDING

None.

\section{REFERENCES}

1. Hopper DW, Crombie AL, Clemens JJ, Known S. Six-membered ring systems: Pyridine and benzo derivatives. Prog Heterocycl Chem 2009;21:330-74.

2. Dansena H, Dhongade HJ, Chandrakar K. Pharmacological potentials of pyrimidine derivative: A review. Asian J Pharm Clin Res 2015;8:171-7.

3. Manlove A, Groziak MP. Six-membered ring systems: Diazines and benzo derivatives. Prog Heterocycl Chem 2009;21:375-414.

4. Brown DJ. Comprehensive Heterocyclic Chemistry. Vol. 14. Oxford, UK: Pergamon Press; 1984.

5. Soni HI, Patel NB. Pyrimidine incorporated Schiff base of isoniazid with their synthesis, characterization and in vitro biological evaluation. Asian J Pharm Clin Res 2017:10:209-14.

6. Elderfield RC. Heterocyclic Compounds. Vol. 6. New York, USA: John Wiley \& Sons; 1957.

7. Jat B, Santra S, Santra PK. Synthesis and evaluation of antimicrobial activity of pyrimidine derivatives. Asian J Pharm Clin Res 2019;12:156-63.

8. Bruice PY. Organic Chemistry. $3^{\text {rd }}$ ed. Singapore: Pearson Education; 2007.

9. Kappe CO. 100 years of the biginelli dihydropyrimidine synthesis. Tetrahedron 1993;49:6937-63.

10. Sharma P, Rane N, Gurram VK. Synthesis and QSAR studies of pyrimido $[4,5-\mathrm{d}]$ pyrimidine-2, -dione derivatives as potential antimicrobial agents. Bioorg Med Chem Lett 2004;14:4185-90.

11. Amir M, Javed SA, Kumar H. Pyrimidine as anti-inflammatory agent: A review. Indian J Pharm Sci 2007;68:337.

12. Abd El-Aleama RH, Georgeb RF, Hassanb GS, Abdel-Rahman HM. Synthesis of 1, 2, 4-triazolo [1, 5-a] pyrimidine derivatives: Antimicrobial activity, DNA Gyrase inhibition and molecular docking. Bioorg Chem 2020;94:103411.

13. Panneerselvam T, Mandhadi JR. Microwave assisted synthesis and 
antimicrobial evaluation of novel substituted thiosemicarbazide derivatives of pyrimidine. J Heterocycl Chem 2020;20:1-7.

14. AlNeyadi SS, Salem AA, Ghattas MA, Atatreh N, Abdou IM. Antibacterial activity and mechanism of action of the benzazole acrylonitrile-based compounds: In vitro, spectroscopic, and docking studies. Eur J Med Chem 2017;136:270-82.

15. Mantipally M, Gangireddy MR, Gundla R, Badavath VN, Mandha SR, et al. Rational design, molecular docking and synthesis of novel homopiperazine linked imidazo [1, 2-a] pyrimidine derivatives as potent cytotoxic and antimicrobial agents. Bioorg Med Chem Lett 2019;29:2248-53.

16. Farag AM, Fahim AM. Synthesis, biological evaluation and DFT calculation of novel pyrazole and pyrimidine derivatives. J Mol Str 2019;1179:304-14.

17. Shehab WS, Assy MG, Moustafa HY, Abdellattif MH, Rahman HM. Pyrimidines as block units in heterocycles: Novel synthesis of pyrimidines and condensed pyrimidine derivatives. J Iran Chem Soc 2019;16:2451-61.

18. Al-Bogami AS, Saleh TS, Moussa TA. Green synthesis, antimicrobial activity and cytotoxicity of novel fused pyrimidine derivatives possessing a trifluoromethyl moiety. Chem Select 2018;3:8306-11.

19. Dofe VS, Sarkate AP, Shaikh ZM, Jadhav CK, Nipte AS, Gill CH. Ultrasound-assisted synthesis of novel pyrazole and pyrimidine derivatives as antimicrobial agent. J Heterocyl Chem 2018;55:756-62.

20. Veeraswamy B, Madhu D, Dev GJ, Poornachandra Y, Kumar GS, Kumar CG, et al. Studies on synthesis of novel pyrido [2, 3-d] pyrimidine derivatives, evaluation of their antimicrobial activity and molecular docking. Bioorg Med Chem Lett 2018;28:1670-5.

21. Mohamed MM, Khalil AK, Abbass EM, El-Naggar AM. Design, synthesis of new pyrimidine derivatives as anticancer and antimicrobial agents. Synth Commun 2017;47:1441-57

22. Andrews B, Komathi K, Mohan S. Synthesis and comparing the antibacterial activities of pyrimidine derivatives. J Chem Sci
2017;129:335-41.

23. Khalifa NM, Nossier ES, Al-Omar MA, Amr AE. Synthesis, reactions, and antimicrobial activity of some novel fused thiazolo [3, 2-a] pyrimidine-5H-indeno [1, 2-d] pyrimidine derivatives. Russ J Gen Chem 2016;86:1948-53

24. Okasha RM, Albalawi FF, Afif TH, Fouda AM, Al-Dies AM, ElAgrody AM. Structural characterization and antimicrobial activities of 7H-Benzo [h] chromeno [2, 3-d] pyrimidine and 14H-Benzo [h] chromeno [3, 2-e] $[1,2,4]$ triazolo $[1,5-\mathrm{c}]$ pyrimidine derivatives. Molecules 2016;21:1450.

25. Prabhakar V, Babu KS, Ravindranath LK, Latha J. Design, synthesis, characterization and biological activity of novel thieno [2, 3-d] pyrimidine derivatives. Indian J Adv Chem Sci 2017;5:30-42.

26. Al-Juboori SB, Mahmood AA. Synthesis, antimicrobial evaluation, density functional theory, and docking studies of some new 2-mercapto pyrimidine Schiff bases. Asian J Pharm Clin Res 2019;12:496-502.

27. Khatri TT, Shah VH. Effective microwave synthesis of bioactive Thieno [2, 3-d] pyrimidines. J Chil Chem Soc 2017;62:3354-58.

28. Triloknadh S, Rao CV, Nagaraju K, Krishna NH, Ramaiah CV, Rajendra W, et al. Design, synthesis, neuroprotective, antibacterial activities and docking studies of novel thieno [2, 3-d] pyrimidinealkyne Mannich base and oxadiazole hybrids. Bioorg Med Chem Lett 2018;28:1663-9.

29. Gupta YK, Gupta V, Singh S. Synthesis, characterization and antimicrobial activity of pyrimidine based derivatives. J Pharm Res 2013;7:491-5.

30. Venkatesh T, Bodke YD, Joy NM, Vinoda BM, Shiralgi Y, Dhananjaya BL. Synthesis of some novel 5, 7-disubstituted-2-phenyl$5 \mathrm{H}-[1,3,4]$ thiadiazolo [3, 2-a] pyrimidine derivatives and evaluation of their biological activity. Lett Org Chem 2016;13:1-11.

31. Madawali IM, Kalyane NV, Gaviraj EN, Shivakumar B. Synthesis and antimicrobial activity of some new pyrimidines of 6-chlorobenzimidazoles. Orient J Chem 2018;34:1633-7. 